\title{
HPV-Mediated (p16-Positive) Oropharyngeal Cancer Pathologic Regional Lymph Nodes TNM Finding v8
}

National Cancer Institute

\section{Source}

National Cancer Institute. HPV-Mediated (p16-Positive) Oropharyngeal Cancer

Pathologic Regional Lymph Nodes TNM Finding v8. NCI Thesaurus. Code C132867.

A pathologic finding about one or more characteristics of HPV-mediated (p16-positive) oropharyngeal cancer, following the rules of the TNM AJCC v8 classification system as they pertain to staging of regional lymph nodes. 